\title{
LA ASPIRACIÓN AL CONOCIMIENTO POÉTICO: EL SÍMBOLO DEL “OJO INTERIOR” EN MARIANA SANSÓN ARGÜELLO
}

\author{
Jorge Chen Sham
}

\begin{abstract}
RESUMEN
El símbolo del "ojo interior" se identifica en nuestra tradición occidental con el intelecto, la razón o la perspicacia; la metáfora de lo ocular en la poeta nicaragüense Mariana Sansón Argüello se transforma en la base de todo nuestro sistema de percepción, una forma superior de conocimiento en la que este ojo interior examina y escruta, para insistir en la necesidad de que la mirada de entendimiento clarifica y puede dar certeza de las cosas.

Palabras clave: Mariana Sansón Argüello, poesía nicaragüense, Las horas y su voces y otros poemas, el ojo interior, poesía metafísica.
\end{abstract}

\begin{abstract}
The symbolism of the "inner eye" is identified within western tradition with intellect, reason or shrewdness. The metaphor of this inner eye by the Nicaraguan poet Mariana Sansón Argüello is transformed as the basis of our total perceptual system, a superior form of understanding in that this inner eye examines and scrutinizes, insisting on the necessity of this view of understanding which clarifies and gives certainty to the issues discussed.

Key words: Mariana Sansón Argüello, Nicaraguan poetry, The Hour and its Voices, and other poems, the inner eye, metaphysical poetry.
\end{abstract}

Mariana Sansón Argüello (1918-2002) comprende, muy tempranamente, que la poesía es ante todo una indagación, una empresa introspectiva y de raigambre mística, en cuanto solamente la palabra depurada y distanciada posibilita la búsqueda del yo poético en el cosmos. Al centrarnos en Las horas y su voces y otros poemas (1996) ${ }^{1}$, domina una sistemática de la percepción; ojos y mirada son partícipes de una simbología que pone su acento en la capacidad cognoscitiva. Ello no es casual en una poesía que se plantea como conocimiento puro y hace

Dr. Jorge Chen Sham. Profesor de la Escuela de Filología, Lingüística y Literatura, Universidad de Costa Rica San Pedro, San José, Costa Rica.

Correo electrónico: jorgechsh@yahoo.com

Recepción: 14-6-2007

Aceptación: 10-7-2007 
del ojo el "símbolo de la percepción intelectual" (Chevalier y Gheerbrant 1995: 770). En tanto "símbolo de la inteligencia y del espíritu, el acto de ver expresa una correspondencia a la acción espiritual y simboliza, en consecuencia, el comprender" (Cirlot 1994: 339). Sin embargo, en el discurso de la lírica, quien realiza el acto de ver, el observador, puede confundirse con la persona que habla ${ }^{2}$; este sincretismo es propio de quien habla y se habla a sí mismo simultáneamente. Por esta razón, podemos caracterizar los acciones verbales de este hablante lírico: a) desde el nivel de lo cognitivo, pues "lo identificamos por lo que sabe y hace saber, por lo que interpreta" (Lozano et al. 1989: 132); y b) desde el nivel de lo perceptivo, "por lo que ve, oye, siente, etc." (Lozano et al. 1989: 132). Así, la hablante lírica se identifica como poeta y nos invita a compartir, a través del acto poético, los procesos mentales internos y las consecuencias que para su percepción del mundo exterior ocurren en ella, con lo cual nos devela su camino de aprendizaje e iniciación a la Poesía.

En ello radica la más pura concreción del acto poético, en donde el acento es puesto en el viaje de exploración del lenguaje y de la realidad, nunca completo y singular (Debicki 1987: 26)33; por ello, el poeta solamente puede captar la realidad a través de la poesía y es conditio sine qua non. La singularidad de la creación poética es del orden de un proceso de conocimiento; de ahí "su irreductibilidad a otros modos de conocer y decir" (Debicki 1987: 25). Mariana Sansón apela a ese "ojo interior", que es del dominio de la observación y del autoconocimiento. Se trata de una de las cuestiones fundamentales de la filosofía occidental. En efecto, desde Sócrates, el problema estriba en diferenciar aquello que separa las bestias del hombre; de ahí la distinción entre el "ojo del cuerpo" y el "ojo interior" (ojo de la Mente) para identificar este último con el intelecto, la razón o la perspicacia. La metáfora de lo ocular se transforma en la base de todo nuestro sistema de percepción: "La idea de la 'contemplación', del conocimiento de los conceptos o verdades universales [...], convierte al Ojo de la Mente en el modelo inevitable de la forma superior de conocimiento" (Rorty 1989: 44). Este ojo interior examina y escruta, de manera que pasa revista a las sensaciones y a los conceptos aclarándolos y distinguiéndolos, es decir, ese espacio interior clarifica y ordena. A ese ojo interior se refiere Mariana Sansón en "Ojo de ojo..." para insistir en la necesidad de que la mirada de entendimiento clarifica y puede dar certeza de las cosas:

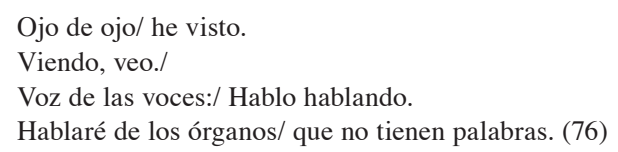

Observemos la correlación entre los verbos "ver" y "hablar". Delinean el proceso intelectivo en una circularidad asombrosa en distribución inversa: "Viendo, veo." $\Leftrightarrow$ "Hablo hablando". Con ello, la poeta reafirma su calidad de vidente que presta su "ojo interior" para que las cosas se revelen y tengan realidad concreta, porque dar voz tiene aquí el mismo sentido que tiene en el relato de la creación del "Génesis" y en la filosofía presocrática; dar voz significa crear. Por otra parte, en poemas como "Se juntaron los ojos..." y "Sólo una luz...", el oído y los ojos se transforman en los órganos sensoriales del conocimiento, ya que como señala Ludwig Schrader, ellos son "los sentidos espirituales más excelentes — de acuerdo con la concepción platónica-cristiana" (1975: 342). Al permitir la captación más elevada de la poesía, estos dos poemas ponen su acento en la expresividad del acto poético, en donde biografía personal y destino artístico se interrelacionan. En "Se juntaron los ojos...", la meditación y el silencio provocan la intensificación tanto de ojos como de oídos y desembocan en la unión de los contrarios noche/ día: 
Se juntaron los ojos; / y en la noche

se calla el sol.

No fue la hierba,/ que de mi cuerpo llega.

Fue la Sal del Espíritu,/ que ya estaba en mi boca. (28)

El poema otorga a la noche estatuto simbólico; es el tiempo perfecto para apelar a la imaginación creadora y a la exaltación poética (Béguin 1993: 106-7), al convocar las fuerzas insondables del cosmos. Con ello se revela lo invisible y se exaltan dos cosas: la visión primordial del poeta vidente y la unidad esencial de la poesía, por medio de una contraposición que remite a un ascenso místico: "No fue la hierba/ [...]. Fue la Sal del Espíritu". Reconstituir esa unidad primordial es función únicamente del poeta, al entender "que ya estaba en [su] boca" la palabra poética y que su oficio es revelar solamente lo que existe por antonomasia y es indivisible.

Recordemos que "[1]a misión de la poesía es recrear el lenguaje primitivo, restituir en su integridad la contemplación asombrada de la primera presencia de las cosas" (Béguin 1993: 83, la cursiva es del autor) ${ }^{4}$. Por eso, "Súplica de mirada..." desemboca en la percepción de la unidad en el instante mismo de la intuición poética: la hablante lírica, transformada ahora en poeta, nos invita a concentrarnos y a distanciarnos a través de la mirada, pues cuando el hombre mira en el espejo del universo, se conoce y ve hacia el interior. Tampoco olvidemos las connotaciones del simbolismo del "ojo" en el imaginario occidental; en este sentido, Luce López Baralt examina la importancia de los ojos en la vía unitiva de la experiencia mística, en donde "la fuente del conocimiento espiritual último refleja unos misteriosos ojos en el momento justo de la transformación mística" (1996: 167). En "Súplica de mirada...", ese ojo único es la imagen del "ojo frontal” que está unido a la idea de la destrucción/purificación (Cirlot 1994: 339):

Súplica de mirada: / El ojo está en el tiempo.

El universo en 1lamas/ la fragua enciende. (35)

En el poema la concentración del tiempo se apodera de la hablante lírica y el tiempo fluye, para subrayar lo que Guillermo Sucre denomina como la intensidad temporal del instante. En primer lugar, se trata de "[v]ivir el tiempo como presente, en verdad, es ya no estar en el tiempo, como si éste fuese ajeno a nosotros, sino ser el tiempo mismo" (1975: 385, la cursiva es del autor); en segundo lugar, la palabra surge del fuego, fuerza creadora, incandescente y purificadora que todo lo transforma, en un desplazamiento sinecdótico altamente significativo: "ojo" $\leftrightarrow$ "universo" $\leftrightarrow$ "fragua", porque el poema establece un sistema de analogías entre la creación del universo siempre en movimiento y el flujo de la creación poética ${ }^{5}$. No es de extrañar, entonces, que tal correspondencia desemboque, en "Súplica de mirada...", en dos afirmaciones: la energía creadora que engendra la palabra; la poeta que ofrece su "mano", su instrumento para que aquélla tome forma, como si ella fuera un conducto para que esa energía fluya:

No es mi mano.

Es ese tú, que al pasar,/ escribe con mi mano. (35)

Si la hablante lírica sansoniana restituye la unidad primigenia del universo mediante el acto poético, lo hace porque "tiene su fuente en una experiencia absolutamente interior y propiamente religiosa” (Béguin 1993: 99), de la que es su oficiante e intermediario. En ello insiste también "Sólo una luz...", al establecer la reintegración de diverso en la unidad de la palabra. Las imágenes esotéricas de la luz irradiada hacia el interior entran en equivalencia con el "eco" del espíritu que cerca la "palabra" 
Sólo una luz/ me ha llegado del ojo.

Un eco no lejano,/ que asedia a la palabra...

En esa concentración de eternidad, en esa vivencia del instante de "Sólo una luz...", el acto poético irradia la fuerza del espíritu e insufla amorosamente al yo lírico, de suerte que la poeta sansoniana atisba, a manera del aleph borgesiano, el Uno en la diversidad, de la que siente partícipe y exclama a viva voz:

Tocando un infinito/ de los otros,

me he puesto a decir esto. (33)

Lo mismo confiesa la poeta en el poema "Mi ojo para el sol...", en donde "el ojo" no solo se convierte en el organon por excelencia, sino que se dibuja esa experiencia del horizonte que lanza y propulsa a la poeta en un vuelo de ascensión purificadora y de búsqueda de la vitalidad inspiradora, pues el ojo único, abierto y sin parpados, es "símbolo de la esencia y del conocimiento divino" (Chevalier y Gheerbrant 1995: 771):

Mi ojo para el sol./ Mi existir para tornar

en aire puro. (37)

Reanimada de esta manera en una existencia que despliega la potencialidad creadora, otra vez el "oído" está ahí para subrayar la visión comprensible de quien sabe captar, en diapasón, el proceso universal y totalizador de la vida:

Casualmente mi oído/ multiplicando audiencias,

me dijo que allí era. (37)

De manera que en Las horas y sus voces opera lo que Albert Béguin observa en la estética romántica, cuando el poeta aspira a esa reintegración con la naturaleza, con el cosmos: "cada individuo sólo vive en proporción a su proximidad al Todo, esto es, en la medida en que una ek-stasis lo arrebatara de la indivualidad" (1993: 98, la cursiva es del autor). Las horas y sus voces se transforman en un poemario cuya impronta está mediada por esa necesidad de que la hablante lírica se religue (religare en su sentido etimológico más prístino) con el universo y hace de ello su indagación esencial. Entonces, reconocer la dimensión religiosa del acto poético es una de las realidades más notables en la primera producción de Mariana Sansón Argüello, en donde "ojos" y "oídos", es decir, saber escuchar y saber ver están al servicio de la capacidad visionaria de la poeta, por lo cual experiencia religiosa e indagación poética se interpenetran.

Lo anterior no es casual si nos percatamos de la modalidad que adquieren muchos de los poemas de esta primera sección a la que hago referencia, al insistir en la capacidad onírica, es decir, de interpretar lo oculto y lo inefable, por ello la noche y los sueños se convierten en la escena primordial para el encuentro de la poeta con esa realidad insondable que indaga y desea aprehender. El empeño estará en descubrir las capacidades simbólicas del sueño como aproximación a lo suprasensible. En "He oído mi sueño...", el sueño permite descender al interior del sujeto y captar, estereofónicamente hablando, las realidades profundas; no es casual que para la vidente los sueños no se vean sino que se escuchen, pues se trata de saber auscultar esa espacio interior en donde se dialoga con el "ojo" interior:

He oído mi sueño./ Tiene los pies delgados

y hace frío todo. (53) 
Dos notaciones sensoriales se imponen aquí en la visión sansoniana: la sinestesia lograda en la asociación de elementos de naturaleza distinta subraya lo que experimenta la poeta cuando escucha esas voces misteriosas que le hablan. Y la indeterminación de la escena desemboca en la revelación. Lo significativo en Mariana Sansón Argüello es que la percepción, obtenida en el sueño, se construya con una sensibilidad arquitectónica de inmensidad y volumen de espacios; esto no es inocente, Michel Collot relaciona esta capacidad visionaria a la metáfora del horizonte. Ésta acentúa "la dimension vertigineuse d'une expérience" (1989: 41) en la que el horizonte es, según la hablante lírica, principio de apertura gracias al cual una atmósfera de inteligibilidad permite efectuar la comprensión de las cosas, transformadas ahora en "verdades"; de ahí que, en estética, el conocimiento se alíe a la imaginación para desplegarse sin ataduras lógicas o normativas, y está al servicio de las "verdades" que el arte vehiculiza y la poeta ahora capta (Cordero 1999: 95):

Meditando en espacios,/ de las cosas me llegan

las verdades. (53)

Decíamos que el horizonte es principio de apertura y lo es porque no puede clausurarse sobre una completud engañosa y ontológica. Sin lugar a dudas, la experiencia poética sansoniana debe comprenderse en el ámbito de una fenomenología de la percepción, tal y como se explicita en "Me lo repito...", en donde el acceso al conocimiento ni es irreductible ni tampoco totalizante a la experiencia humana:

\footnotetext{
Me lo repito,/ pero no lo poseo.

El ojo del espíritu/ se abre a ratos

y te deja medir/ en las distancias. (53)
}

La poeta leonesa siente un impulso por comprender las cosas y encontrar en ellas un significado esclarecedor; pero el acto poético en cuanto experiencia del horizonte significa no tanto hablar sobre las cosas, sino dejar que ellas tomen forma y se expresen en virtud de la palabra: la poeta es el medio; la palabra, el canal. Por ello, el poeta que configura el discurso sansoniano no es dueño de la Poesía, no la posee; más bien la contempla invitándonos al movimiento y al contacto purificador ("y te deja medir/ en las distancias"). Así, la poeta, que dibuja Mariana Sansón en "He oído mi sueño...", tiene el privilegio de escuchar, ver y palpar la luz que irradia ese "ojo del espíritu" en el marco del sueño, prefiguración de ese momento bienaventurado en que la gnosis acompaña la fruición amorosa e irradia el espacio de la escritura. Veamos como termina el poema "He oído mi sueño...": "Y a veces en el sueño,/ leo $[10]^{6}$ escrito" (53).

Por otro lado, dentro de esta retórica de las visiones y sueños, encontramos en Mariana Sansón el motivo de los ojos multiplicados; Cirlot subraya que la multiplicación de los ojos se relaciona con "la noche, con sus miríadas de estrellas y entenebrece, pues, paradójicamente al poseedor de tantos ojos" (1994: 339); de ahí que estamos en el terreno del inconsciente y de lo onírico. Por ejemplo, en el poema "Los ojos...", esos ojos convocan el espacio de la noche en la que vuelven a triunfar la imaginación creadora y la ensoñación. El poema nos invita a comprender que otra sensibilidad distinta se impone para captar el enigma del cosmos:

Los ojos/ revelan la noche.

Un espíritu ronda/ cuando suena el frío.

Se sienta en las piedras/ a descansar;

y va interpretando/ los saludos. (72) 
El estatuto simbólico de la noche se aprecia en notaciones creadoras de una atmósfera de incertidumbre y de oscuridad: el frío, el silencio, la soledad se imponen para marcar esa oportunidad inaudita que tiene la hablante lírica; dos verbos traducen esa necesidad espiritual de conocimiento: "revelan" y "va interpretando". Se trata de descifrar aquello que se presenta como desconocido e incierto; de ahí que surja la figura del pensador sentado sobre piedras con la finalidad de insistir en el acto de meditación y de reflexión al que es invitada la poeta. Por su parte, como esos ojos multiplicados se asocian a lo inconsciente, "Nuevos ojos..." traduce esa nostalgia de lo infinito que Aguiar e Silva asocia a la meditación de la noche (1979: 323):

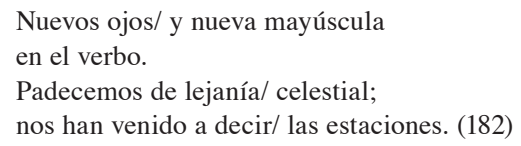

La insatisfacción espiritual del yo lírico se aprecia en la significación del verbo "padecer", para quien se erige una distancia insondable que lo separa de la transcendencia divina y el tiempo avanza escrupulosamente sin que el hombre pueda controlarlo. La incapacidad del hombre, mortal hay que decir, se explicita en el sentido que posee la forma verbal "han venido a decir"; es un verbo impersonal eventual, el cual subraya que otra es la fuerza agente creadora de "las estaciones", del tiempo. El hombre solamente lo padece.

Por último, cabe agregar otra significación de esos ojos multiplicados o heterotópicos, es decir, desplazados a lo largo de ese horizonte que se perfila ante la mirada de la hablante lírica. Para Cirlot, aquellos "aluden al correlato espiritual de la visión [...], a la clarividencia" (1994: 339). En "Riego los ojos...", la acción de regar, que contiene el sema de lo acuático y, por lo tanto de la fecundidad, aparece aquí para ofrecernos la visión de los cuatro elementos integrados en la acción de la poeta sansoniana:

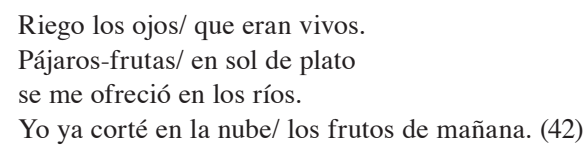

Sólo la luz de la mirada permite ahora "regar" los ojos, símbolos de luz y de la sabiduría. Se trata de "la vía del conocimiento [mediante] la palabra penetrada más allá de lo empírico" (Santos Silva 2001: 66), por lo cual la Poesía se transforma en ese camino hacia el "pleno conocimiento del misterio que nos encarna" (Santos Silva 2001: 66)7. De esta manera, los cuatro elementos se despliegan en esta visión del acto poético, gracias a una imagen de gran transcendencia, ya que emplazan la transformación de los "[s]ímbolos de lo elemental y puro" (Alonso 1968: 249), porque "las más diversas cosas, unificadas, reducidas a su básico y común valor, le envuelven [...], todo se reduce al incesante movimiento de desintegración y caducidad" (Alonso 1968: 251, la cursiva es del autor) ${ }^{8}$. En los versos "Pájaros-frutas/ en sol de plato/ se me ofreció en los ríos", Mariana Sansón rinde tributo a esa unión del aire y de la tierra en la creación poética de los "pájaros-frutas", bajo la intervención del fuego ("en sol de plato") y del agua ("en los ríos"). El fuego subraya el esfuerzo de concentración en la intensidad de una luminosidad que aporta la maduración (Séguin 2001: 88) de estas frutas maravillosas, mientras que el agua ofrece esa elasticidad necesaria para que se imponga la fuerza creadora del cosmos 9 .

Esta imbricación de los elementos culmina con una descripción de lo que significa, en efecto, el trabajo poético según la descripción sansoniana de la confluencia entre lo superior 
y lo inferior; se trata de una imagen que confirma esa aspiración de inmensidad, de apertura, pues, al cortar "los frutos de mañana", la poeta insiste en la progresión y en la verticalidad de su destino artístico. Curiosamente, tal posibilidad de ascenso se posibilita en una doble acción que realiza la poeta: ver el cosmos (conocerlo) culmina con la recolección de lo vegetal y el elogio de los símbolos del árbol y la hoja (sembrar o cortar). Este movimiento de exploración de sí misma y su salida hacia el mundo exterior tiene por fuerza la existencia (el ver fuera de sí misma) $\mathrm{y}^{10}$, en la filosofía clásica griega, por ejemplo en Aristóteles, el existir se acompaña del decir ${ }^{11}$ y, en este caso de Mariana Sansón, del decir que se ha visto y soñado:

\begin{abstract}
Existe quien ha salido de sí por la palabra y se ha apropiado de los fundamentos de la "primera materia sujeto [=la lengua] que posee en sí misma el principio de movimiento y cambio". Si la palabra es el salir de sí, gracias al movimiento de las partículas de aire, afirmaremos con Aristóteles, la voz es la exsistencia del alma. El principio anímico íntimo encuentra su realización y materialidad exteriores en la expresión idiomática (Lara-Martínez 2001:194).
\end{abstract}

Doble instrumento para la captación del conocimiento, la lengua (la poesía), y su medium de entonación/ circulación (el poeta), se despliegan en esa oscilación entre Arte y Filosofía. En este sentido, Hegel postulaba que había tres formas para captar el espíritu absoluto, la religión, el arte y la filosofía; en Mariana Sansón, la finalidad artística y el despliegue de sus capacidades filosóficas hacen que "el verdadero contenido del arte [sea] el de la idea" (Cordero 1999: 96) que reuniría, respectivamente, estas tres formas de conocimiento bajo el Ojo integrador del espíritu absoluto. Al respecto, en su Estética Hegel diferencia, para cada una de ellas, tres modalidades del conocimiento que se articulan en forma subsecuente para integrarse en la actividad filosófica:

\footnotetext{
La primera forma de captación es un saber inmediato y por ello sensible, un saber en la forma y figura de lo sensible y objetivo mismo, en el cual lo absoluto llega a la intuición y al sentimiento. La segunda forma es

la conciencia representativa; la tercera, en fin, el pensar libre del espíritu. (Citado por Cordero 1999: 95)
}

Pues bien, a este "pensar libre del espíritu” contribuye Mariana Sansón en una poesía que es manifestación sensible de la idea y forma de intuición de lo absoluto. Desde el camino del conocimiento y sus formas de revelación, gracias a ese símbolo tan conspicuo en nuestro imaginario como es el ojo, descubrimos cómo la hablante lírica, en Las horas y sus voces y otros poemas, perfila en tanto poeta su destino poético y, de esta manera, pone bajo esa guía toda su indagación escritural. No cabe mayor motivo de aspiración y depuración poéticas en una voz lírica auténtica y profunda en la poesía nicaragüense del siglo XX, cuya sencillez formal corre paralelo a un mundo poético entrañable y de gran entramado filosófico.

\title{
Notas
}

1. Posee además la siguiente producción: "Poemas" (Cuadernos Universitarios, León, 1959), Poemas (León, edición a costa de la autora, 1967) y Zoo fantástico (Managua, Instituto Nicaragüense de Cultura/ BANIC, 1994). La biografía completa de la poeta la encontrarán en el libro homenaje Mariana Sansón Argüello: Primer aniversario de su fallecimiento (2002-2003), editado por Edgardo Buitrago Buitrago.

2. Se trata de una de las diferencias fundamentales que propone la narratología con Gérard Genette, para quien el observador no debe confundirse necesariamente con el observador (el punto de vista adoptado), pues "el relato que adopta la perspectiva ora de un personaje[,] ora de otro, puede mantener una uniformidad enunciativa en cuanto a la voz si es una narración en tercera persona, por ejemplo" (Lozano et al. 1989: 132). 
3. En ello coincide Mariana Sansón con otras generaciones de poetas en lengua española, los cuales plantean un concepto de creación poética como una forma de conocimiento; ejemplo de ello lo encontramos en la Generación de los 50 española, cuyos representantes más conspicuos son José Ángel Valente, Francisco Brines, Jaime Gil de Biedma y Claudio Rodríguez. En su ensayo "Conocimiento y comunicación", publicado por Francisco Ribes (Poesía última: selección. Madrid: Ediciones Taurus, 1963), José Ángel Valente afirma: "La poesía aparece así, de modo primario, como revelación de un aspecto de la realidad para el cual no hay más vía de acceso que el conocimiento poético" (1963:10).

4. Idea clave en la estética del romanticismo; sobre este punto comenta Béguin: "En el estado actual de las cosas, el hombre conserva, en el fondo de sí mismo, los despojos de su primer destino y la oscura reminiscencia del paraíso primitivo. Si logra escuchar los signos interiores que le son dados, si logra descender de nuevo en sí mismo hasta poder adueñarse una vez más, por medio de una magia puramente espiritual de los gérmenes que se incuban en su alma, realizará su propia reintegración en Dios y, al mismo tiempo, restituirá su unidad primordial a la creación entera" (1993: 80). Vasto programa que se perfila en la creación poética de Mariana Sansón.

5. Se trata, al mismo tiempo, de un proceso constante de movimiento y de flujos, como si Mariana Sansón se imaginara ese universo en ebullición y en constante cambio, de ahí que la desintegración y la anulación se encuentren; por ejemplo en el poema "Vi sobre el agua...." "Vi sobre el agua:/ Se movían los ojos./ Con una sola mano/ se acomodaban alas/ que crecían despacio./ El mismo cementerio/ de hojas es silencio" (62).

6. Corrijo lo que me parece una errata del poema.

7. Tales coincidencias hacen que lo planteado aquí por Mariana Sansón se ajuste al pensamiento poético de Eunice Odio, la gran poeta costarricense, en su poemario Los elementos terrestres (Guatemala 1948).

8. Denominación que emplea Amado Alonso para la poesía de Pablo Neruda. En este sentido, habría que pensar esta "caducidad" como el principio del proceso complementario y reversible, todo cambio de desintegración debe conducir a la reintegración, del caos de los elementos vamos hacia su nueva unidad, siguiendo el principio filosófico de "Todo es uno y lo mismo" (Alonso 1968: 252).

9. Para Chevalier y Gheerbrant, el río, por antonomasia, está asociado a la imagen del flujo de las aguas y, por lo tanto, símbolo de "la fertilidad, la muerte y la renovación" (885). Más adelante ellos indican lo siguiente: "Descendiendo de las montañas, serpenteando a través de los valles, el río simboliza la existencia humana y su flujo, con la sucesión de deseos, de los sentimientos, de las intenciones [...]” (1995: 886).

10. Esto lo indica Rafael Lara-Martínez para el caso de la hermenéutica poética de Eunice Odio; véase el artículo citado en la Bibliografía.

11. En la voz radicaba el acto de creación; se trata de subrayar el valor performativo de la creación, en donde el decir y el hacer se confunden. La performatividad del lenguaje tiene que ver con aquellas expresiones verbales que no describen "nada exterior al propio acto de enunciarlas -y poseen la función específica de cumplir una acción" (Lozano et al.: 174, la cursiva es de los autores). Son verbos cuya enunciación equivale a cumplir la acción contenida en el verbo. En Cómo hacer cosas con palabras: Palabras y acciones, John L. Austin plantea que son verbos realizativos aquellos del tipo "decir algo es hacer algo; o en los que porque decimos algo o al decir algo hacemos algo" (53, la cursiva es del autor). En la esfera de la creación poética, decir algo es nombrarlo; el acto poético de decir es suficiente para su realización. 


\section{Bibliografía}

Aguiar e Silva, Vítor Manuel. 1979. Teoría de la literatura. $3^{a}$ reimpr. Madrid: Editorial Gredos.

Alonso, Amado. 1968. Poesía y estilo de Pablo Neruda: Interpretación de una poesía hermética. $2^{\mathrm{a}}$ ed. Buenos Aires: Editorial Sudamericana.

Béguin, Albert. 1993. El alma romántica y el sueño: Ensayo sobre el romanticismo alemán y la poesía francesa. $2^{\text {a }}$ reimpr. Madrid: Fondo de Cultura Económica.

Buitrago Buitrago, Edgardo (ed.). 2003. Mariana Sansón Argüello: Primer aniversario de su fallecimiento (2002-2003). León: Editorial Universitaria.

Cirlot, Juan-Eduardo. 1994. Diccionario de símbolos. $3^{\text {a }}$ ed. Barcelona: Editorial Labor.

Chevalier, Jean y Alain Gheerbrant. 1995. Diccionario de los símbolos. $5^{\mathrm{a}}$ ed. Barcelona: Editorial Herder.

Collot, Michel. 1989. La poésie moderne et la structure d'horizon. París: Presses Universitaires de France.

Cordero, Allen. 1999. "La interesada imaginación poética". Revista de Filosofía de la Universidad de Costa Rica. 37 (91): 91-99.

Debicki, Andrew P. 1987. Poesía del conocimiento: La generación española de "1956-1971”. Gijón: Ediciones Júcar.

Lara-Martínez, Rafael. 2001.“La identidad del aire: Poesía y Filosofía” en El tránsito de fuego. La palabra innumerable: Eunice Odio ante la crítica. Jorge Chen Sham y Rima de Vallbona (eds.). San José: Editorial de la Universidad de Costa Rica/ Instituto Literario y Cultural Hispánico, 173-205.

López Baralt, Luce. 1996. "El 'Cántico espiritual’: El júbilo de la unión transformante”. San Juan de la Cruz an Fray Luis de León (A Commemorative International Symposium, November 14-16, 1991, Hilles Library at Harvard University). Mary Malcolm Gaylord y Francisco Márquez Villanueva (eds.). Newark: Juan de la Cuesta, 145-89.

Lozano, Jorge, Cristina Peña-Marín y Gonzalo Abril. 1989. Análisis del discurso: Hacia una semiótica de la interacción textual. Madrid: Ediciones Cátedra.

Ribes, Francisco. 1963. Poesía última: selección. Madrid: Ediciones Taurus.

Rorty, Richard. 1989. La filosofía y el espejo de la naturaleza. Madrid: Ediciones Cátedra. 
Sansón Argüello, Mariana. 1996. Las horas y sus voces y otros poemas. Managua: Nueva Nicaragua.

1994. Zoo fantástico. Managua: INIC/ BANIC/ INCH.

Santos Silva, Lorena. 2001. "Los elementos terrestres o el materialismo místico". La palabra innumerable: Eunice Odio ante la crítica. Jorge Chen Sham y Rima de Vallbona (eds.). San José: Editorial de la Universidad de Costa Rica/ Instituto Literario y Cultural Hispánico, 65-76.

Schrader, Ludwig. 1975. Sensación y sinestesia. Madrid: Editorial Gredos.

Séguin, Marie-Christine. 2001. Des motifs pour dire les quatre éléments dans l'oeuvre poétique de José Lezama Lima. Villeneuve d'Ascq: Presses Universitaire du Septentrion.

Sucre, Guillermo. 1975. Lamáscara, la transparencia: Ensayos sobre Poesía Hispanoamericana. Caracas: Monte Ávila Editores. 